\title{
AOR
}

Selected Papers of \#AoIR2019:

The $20^{\text {th }}$ Annual Conference of the Association of Internet Researchers Brisbane, Australia / 2-5 October 2019

\section{THE CARRIER WAVE PRINCIPLE}

Aram Sinnreich

American University School of Communication

Jesse Gilbert

Dark Matter Media

\begin{abstract}
Hidden figures long buried beneath classic paintings by Rembrandt, Bruegel, and Picasso are revealed through infrared and x-ray imaging, changing our understanding of cultural and social history. Researchers point a camera at a bag of potato chips stored behind a wall of soundproof glass, and "eavesdrop" on the people in the room with it, by resynthesizing sound waves from the microscopic ripples on the bag's surface. Police arrest former police officer Joseph James DeAngelo as the alleged Golden State Killer, decades after his horrific crimes, based on a match between DNA samples and an open source genealogy website. Analysis of public data from a fitness app reveals the location and movements of secret military bases in war zones such as Syria and Afghanistan. A state judge orders online retail titan Amazon to hand over recordings of a private citizen's household collected by its Echo "smart device" as evidence in a murder trial.
\end{abstract}

Each of these stories has something in common: cultural and technological artifacts (a painting, an app, a bag of chips), placed into new social and institutional contexts, and with the aid of computational technologies, end up revealing far more than their creators originally intended them to, and, in many cases, more than they could have imagined.

Anecdotes such as these are often treated as sui generis novelties, strange episodes at the periphery of normal social, cultural and technological processes. When they are discussed within a broader context, the scope of discussion is typically limited to the particularities of the case: The forensic analysis of old paintings is presented as an unalloyed benefit to art historians; the fitness app data are interpreted as a cybersecurity threat with consequences for America's strategic military interests; the

Suggested Citation (APA): Sinnreich, A. \& Gilbert, J. (2019, October 2-5). The Carrier Wave Principle. Paper presented at AoIR 2019: The $20^{\text {th }}$ Annual Conference of the Association of Internet Researchers. Brisbane, Australia: AolR. Retrieved from http://spir.aoir.org. 
use of Amazon Echo recordings in a murder case revives longstanding debates about the relative social benefits of surveillance and privacy. Not only are these contexts wholly separate from one another, each is framed as contiguous with pre-digital practices and concerns. The addition of computational analysis, therefore, is relegated to little more than a new twist on an old story: Forensic art history adds a new tool; military security faces a new threat.

While each of these contexts is certainly appropriate for the case study in question, and each site-specific discussion deserves merit in its own right, we argue in this article that the broader principle which unites them is also worthy of investigation, and may have profound implications for media studies as a field of research, and for media as a site of social action. Individually, the examples we cite may represent historical continuity within their separate spheres, but collectively they represent a distinct rupture in the relationship between media and society, and require us to reinvestigate our assumptions about culture, technology, and policy, as well as the interdependencies among them.

Specifically, we argue that, while anecdotes such as those we have cited are commonly understood and presented as proverbial "exceptions that prove the rule," or what are often referred to as "edge cases," in the parlance of engineering and law (Powell, 2015), and therefore notable for their ambiguous ethics or interpretive valence, they are actually exemplary of a much broader principle that applies to all cultural artifacts, which for reasons that will become clear, we refer to as the "carrier wave principle." The rudiments of this principle can be summarized thus:

- There is no theoretical limit to the amount and variety of knowledge that may be produced from a given cultural artifact. This may be understood as analogous to the mathematical concept of "n-way," often used in computer science (e.g. Carroll \& Chang, 1970; Kolda \& Bader, 2009), to describe a limitless set of possible relationships among elements within or between data sets.

- As a given artifact is displaced temporally, geographically, and/or culturally from its origins, the tacit assumptions and omissions intrinsic to the circumstances of its production become increasingly evident, an epistemic shift that reframes the artifact not merely as a transmissive vessel for information, but as a site of inquiry itself. This n-way process is iterative and lateral, and as one episteme gives way to or competes with another (Foucault, 2005), multiple "layers" of knowledge may be produced from the same artifact.

- These two interrelated conditions are immanent to mediated culture, and have been discussed, in various ways, by social theorists for thousands of years. They are both premised on a dialectical relationship between technology, on the one hand, and culture, on the other.

- The addition of ubiquitous computational processing to a globally networked communications infrastructure has "technologized" culture in a way that collapses this dialectic, eliminating the distance between production, transmission, archiving, reception, and analysis. The sociotechnical affordances of this newly 
synthetic cultural infrastructure have catalyzed a cascade of new epistemes, which are so numerous and diverse that they challenge the capacity of individuals, communities, and institutions to adapt.

The challenges precipitated by the digitization of culture have been discussed extensively in terms related to crises of social institutions and power, including the need for "big data ethics" (boyd \& Crawford, 2012), the disruptions to traditional media and communications industries (Craig \& Cunningham, 2019), and the dangers of algorithmic governance (Gillespie, 2018). Our aim in this article is to raise an additional crisis, which we view as causally proximate to the others: namely, that as the cultural infrastructure has become increasingly technologized, everyday users have become commensurately less capable of understanding the consequences of their actions and interactions. Specifically, they are largely unaware, and uninformed, about the layers of knowledge that may be produced by any number of third parties from their creative, consumptive, and communicative practices.

In short, digital technology - marketed to consumers as a tool of social progress and individual empowerment - has for the most part been designed and deployed to achieve fundamentally different ends. Primary among these is the production, stockpiling, synthesis, and commercial and political exploitation of data about users (West, 2019). In this article, we argue that, in order to develop cultural competencies, practices, and institutions necessary for digital technology to deliver on its promises, we must first theorize the conditions under which it has failed to do so.

\section{References}

boyd, d., \& Crawford, K. (2012). Critical questions for big data: Provocations for a cultural, technological, and scholarly phenomenon. Information, communication \& society, 15(5), 662-679.

Carroll, J. D., \& Chang, J. J. (1970). Analysis of individual differences in multidimensional scaling via an N-way generalization of "Eckart-Young" decomposition. Psychometrika, 35(3), 283-319.

Craig, D., \& Cunningham, S. (2019). Social Media Entertainment: The New Intersection of Hollywood and Silicon Valley. New York: NYU Press.

Foucault, M. (2005). The order of things. New York: Routledge.

Gillespie, T. (2018). Custodians of the Internet: Platforms, content moderation, and the hidden decisions that shape social media. New Haven, CT: Yale University Press.

Kolda, T. G., \& Bader, B. W. (2009). Tensor decompositions and applications. SIAM review, 51(3), 455-500.

West, S. M. (2019). Data Capitalism: Redefining the Logics of Surveillance and Privacy. Business \& Society, 58(1), 20-41. https://doi.org/10.1177/0007650317718185 